\title{
A RESENHA ON LINE NO BRASIL: POSSIBILIDADES DE PRODUÇÃO DE CONTEÚDO COLABORATIVO
}

\section{THE ON LINE REVIEW IN BRAZIL: POSSIBILITIES OF COLLABORATIVE CONTENT PRODUCTION}

Ed Porto Bezerra

Universidade Federal da Paraíba

edporto@di.ufpb.br

\author{
João Batista Firmino Júnior \\ Universidade Federal da Paraíba \\ firminojunior83@gmail.com
}

\begin{abstract}
Resumo: $O$ artigo aborda a maneira como a resenha brasileira adaptou-se ao universo on line, sobretudo em permitir uma maior colaboração do leitor. A problemática envolve a forma como mecanismos hipermidiáticos e interativos são usados e interferem na produção e na potencialização do texto. Isso se dá em espaços para comentários e nas ligações com fóruns e hiperlinks. Através da análise de sites de resenha on line, percebemos uma nova forma de interagir com resenhas. Esta permite ao leitor a possibilidade de tecer críticas ao produto avaliado e à própria resenha, ajudando a construir uma informação coletivizada. Concluímos que o usuário tem mais facilidades para colaborar.
\end{abstract}

Palavras-chave: Resenha, On line, Produção de Conteúdo Colaborativo.

Abstract: The article approaches the way Brazilian review adapted to the online universe, especially in permitting a bigger collaboration to the reader. The problematic involve the way in which hypermedia and interactive mechanisms are used and interfere in the production and potentiation of the text. This takes place in websites for comments, in calls with forums and hyperlinks. Through the analysis of online review websites we perceived a new form of interacting with it. The latter allows the reader the possibility of criticizing the product to be evaluated and the review as well, helping to create collective information. We conclude that the user has easier ways to collaborate.

Keywords: Review, On line, Collaborative content.

\section{Introdução}

Este artigo pretende, sobretudo, abordar as possibilidades do uso colaborativo da resenha on line brasileira na produção de conteúdo.

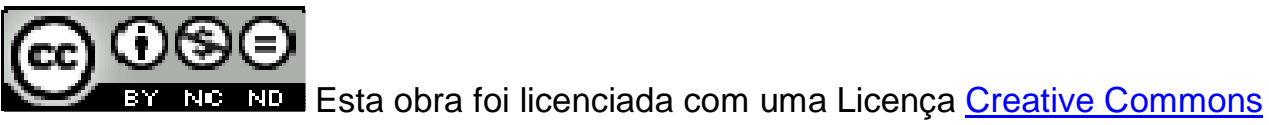

Texto Digital, Florianópolis, v. 7, n. 1, jan./jun. 2011. ISSNe: 1807-9288 
Segundo Marques de Melo (1994, p.125), a resenha ou crítica “... corresponde a uma apreciação de obras de arte ou de produtos culturais, com a finalidade de orientar a ação dos fruidores ou consumidores". A partir desse entendimento básico, iremos inferir como esse tipo de texto adaptou-se à Internet, ao mesmo tempo respondendo a certos anseios socioculturais, sobretudo no que diz respeito a novos gêneros culturais a serem analisados, como por exemplos jogos eletrônicos e histórias em quadrinho.

Começamos com descrições e comparações iniciais entre os sites Omelete (2011), O Capacitor (2011) e UOL Jogos (2011). Deles coletamos material necessário para entender sua configuração, bem como até que ponto existe uma real colaboração na construção da informação, tendo por ponto de partida a resenha on line, num espaço capaz de permitir novas avaliações.

O objetivo é entendermos a capacidade de estruturação do texto opinativo na web, em uma construção que possui um eixo (o texto-origem) que media suas diferentes possibilidades hipermidiáticas, seus trailers e álbuns de imagens, bem como sua hipertextualidade. Isto nos remete à construção de algo de aspecto poroso e bem encadeado.

As possibilidades interacionais que almejamos nesta investigação permitem não mais um mero olhar em relação ao produto, mas uma participação onde opiniões coexistem com outras, em ritmos diferentes, expondo melhor os acertos e os desacertos do produto cultural.

Tem-se, agora, um espaço que pode também ser adequado à crítica da própria resenha, de uma forma ou de outra esse processo possibilita a criação de novas análises, levando ao desmonte e à reconstrução, várias vezes, do conjunto informacional do texto crítico original. Por outro lado, há recursos que não estão sendo explorados. Também há recursos cuja participação não se amplia ao contato direto entre resenhista, produtor e leitor.

Em muitos casos, há uma pseudo-interação onde toda a criatividade do leitor fica restrita a apenas uma enquete ou a um sistema de comentários escondido 
no fim da tela. Nesta pseudo-interação, a frequência de postagens não ocorre "ao mesmo tempo", mas em tempos diferentes, quebrando assim a viabilidade de uma discussão realmente interativa no que diz respeito ao tempo próprio de cada interagente.

Em suma, ao final desta investigação esperamos expor as possibilidades de como as resenhas on line estão se adaptando ao ambiente web e de que forma elas podem contribuir para a reconstrução colaborativa de conteúdos.

\title{
2. A Resenha on line
}

A crítica, antes de dar origem à resenha, sempre foi o alicerce principal do jornalismo cultural brasileiro. Bem antes da Internet, criticavam-se formas de arte como óperas, teatro, literatura etc. Velhos gêneros que demandavam uma maneira própria de avaliação, de acordo com a natureza do produto cultural.

Em um mundo mais moderno, numa era de máquinas e telefones, veio a linguagem do cinema e a necessidade de uma crítica que soubesse abordar esse fenômeno. Sobre isso, temos que:

\begin{abstract}
A primeira metade do século $X X$ parece ser marcada por expectativas quanto à evolução do cinema e da própria crítica, que estão em processo de legitimação concomitante à formação da base conceitual e metodológica para tratar dos filmes, o que se reflete em críticas impressionistas ou em esforços pioneiros de teorização. (BARRETO, 2005, p.23)
\end{abstract}

Vemos, com isso, a necessidade de adaptação da crítica ao tipo de narrativa do produto analisado e, também, o surgimento do que entendemos por "resenha", sendo necessária uma diferenciação entre resenha e crítica tal qual podemos depreender da seguinte forma:

Os grandes intelectuais que continuaram a realizar exercícios críticos estruturados segundo os padrões da análise acadêmica refugiaram-se nos periódicos especializados ou nos veículos restritos ao segmento universitário da sociedade brasileira. E se autodenominaram críticos, em contraposição àqueles que

Texto Digital, Florianópolis, v. 7, n. 1, jan./jun. 2011. ISSNe: 1807-9288 
permanecem nos meios de comunicação coletiva, ou que se agregaram ao trabalho de apreciar os novos lançamentos artísticos, cujos textos passaram a se chamar resenhas, traduzindo a expressão review utilizada pelo jornalismo norteamericano (MELO, 1994, p.126).

Deixemos claro, também, que não estamos trabalhando com as resenhas críticas acadêmicas, mas com aquele tipo de texto voltado ao público geral, menos segmentado e, principalmente, mais perecível.

Assim, continuando, a revolução seguinte, já com o conceito propriamente dito de "resenha", deu-se, finalmente, com a presença do jornalismo cultural criado especificamente para a web. E isso se torna mais presente no Brasil com o surgimento, no ano 2000 , do site Omelete, um site voltado ao entretenimento.

Além desse site, temos incontáveis possibilidades em blogs com algum tipo de apreciação e avaliação própria, sobretudo de filmes, como é o caso do blog de Rubens Ewald Filho ${ }^{1}$, com um tipo de texto que nós também consideramos resenha, adaptado ao universo sequenciado dos blogs e com um forte tom pessoal.

O início disso tudo só se dá realmente com uma mistura de webjornalismo com entretenimento puro, pelo menos no que diz respeito a sites como o Omelete, que junta toda uma base que vem do jornalismo profissional com uma necessidade de apreciação - e de colaborações nessa apreciação - de todo um mercado voltado não aos fatos jornalísticos, mas ao consumo de narrativas digitais feitas a partir do cinema, dos jogos eletrônicos e das revistas em quadrinhos.

Esse mesmo webjornalismo, ao menos aqui no Brasil, tornou-se mais presente no lançamento da primeira cobertura on line, a do Jornal do Brasil, em 1995. Entretanto, naquele início, o que havia era mais um jornalismo transposto. Quer dizer, uma primeira fase que é bem descrita por Palácios et al. (2002), sendo

\footnotetext{
${ }^{1}$ Disponível em: <http://noticias.r7.com/blogs/rubens-ewald-filho/>. Acesso em: 07 maio 2011.
} 
entendida como uma ação transpositiva, onde "... os produtos oferecidos, em sua maioria, eram reproduções de partes dos grandes jornais impressos, que passavam a ocupar o espaço na Internet". Só mais tarde, surgiriam sites com conteúdo jornalístico específico para o universo hipermidiático, sobretudo os de um jornalismo mais especializado no campo do entretenimento cultural.

A partir de tal ponto, nos vemos frente à necessidade de partirmos para uma detida análise de alguns desses sites que contêm o que chamamos de resenhas on line, que dão início a uma nova forma de fazer jornalismo cultural, sem aquela rigidez conceitual da resenha tradicional.

\section{Sites de Resenhas On line}

Nesta seção analisaremos três sites de resenha on line: Omelete, O Capacitor e UOL Jogos. A amostragem escolhida não foi, contudo, totalmente aleatória, pois optamos por sites que nós detectamos estar em uma fase intermediária entre continuidade e ruptura (Omelete e O Capacitor), e o site UOL Jogos que está num estágio mais avançado no que diz respeito à transformação da resenha em análises compactas.

Sobre o que nos referimos como "continuidade", trata-se, justamente, de uma mera transposição de resenhas de jornais ou revistas para o meio digital. Sobre "ruptura" significa uma quebra ao padrão comum, levando a uma reconfiguração de todo o processo comunicativo de acordo com a linguagem multimidiática, digital e convergente da web. Além disso, usamos o termo "potencializações" para designar a possibilidade de aumento da participação, através de processos interativos do público. Para essa situação, escolhemos o site UOL Jogos, que nos pareceu investir mais nessa característica que os outros.

O site Omelete divide seu conteúdo por categorias (Cinema, Quadrinhos e Games, dentre outras) e modalidades textuais (Notícias, Artigos e Críticas). Em termos de resenhas, às quais eles preferem chamar "críticas", sua atividade é prolífica, ao contrário das únicas dez resenhas do site $\mathrm{O}$ Capacitor. Neles, há 
uma valorização de uma conjunção de gêneros midiáticos, mas a maior variedade de informações digitais multimidiáticas encontra-se no site Omelete.

Deparamo-nos, então, com sites cujas resenhas realizam a mediação entre o mundo imersivo do produto cultural avaliado e sua respectiva narrativa, através de uma mensagem que também serve de canal revelando dois caminhos informacionais constituídos pelo contato direto entre receptor e um determinado trailer, imagem ou enredo, e pelo contato paralelo com uma visão própria de um resenhista.

Utilizando-nos de parte da taxonomia completa de Nora Paul (2007), podemos considerar a mídia determinando e sendo determinada por um contexto hipermidiático, totalizando uma comunicação (com uma configuração, tipo e objetivo próprios).

Seguindo essa fórmula, temos um trailer qualquer em simbiose com texto e imagens em um processo que chamamos de interação interna, isto é, entre elementos constituintes do processo de construção da mensagem. Essa interação interna ocorre mais precisamente no site Omelete, que é mais avançado nesse processo de convergência midiática.

Tal interação interna começa com a criação de um eixo entre uma textualidade voltada ao jornalismo opinativo e à web, algo entre dois mundos, ainda em processo de definição, em que ainda resiste a força do texto escrito em relação ao texto imagético e audiovisual, buscando a colaboração de leitores ou usuários que não vão apenas "ler" isso, mas interagir, reativa ou mutuamente (PRIMO, 2008). Isso se dá mais através da mídia em si que do gênero, o que obriga a uma mudança da forma textual, que é só um elemento da resenha a interagir internamente com as características da própria mídia, que é a Internet, entendida como uma conjunção de suportes midiáticos.

O caso do site Capacitor e do site Omelete envolve um início de abertura em termos de colaboração. Entretanto, ainda algo muito incipiente e cujas possibilidades de discussão, ou de colaboração, ao menos indireta, às ideias 
contidas nas resenhas, se dão menos através de comentários na própria página e mais através da interligação, da interconexão com espaços mais apropriados, na própria Internet, como as redes sociais e os fóruns, tirando a primazia do espaço específico da resenha. Os espaços são múltiplos, e a resenha on line deve ser entendida mais como um ponto de partida para a colaboração em outros espaços envolvendo o mesmo assunto ou produto analisado. Espaços que vão da correspondência por e-mail com o autor do texto ao transbordamento de uma discussão para outros fóruns e redes sociais, trazendo o perigo de uma excessiva dispersão.

Consideramos agora o site UOL Jogos que também se utiliza de "análises on line" que são uma derivação do conceito de "resenha". Não temos aqui algo que nasceu da ideia de resenha, mas que partiu para um produto mais prático e adequado ao ambiente web, ou seja, um conjunto composto por sumário, considerações, introdução, pontos positivos e pontos negativos (Figura 1).

Esse fruto da resenha ou, simplesmente, "análise", é mais prático, representando, possivelmente, um futuro para as resenhas.

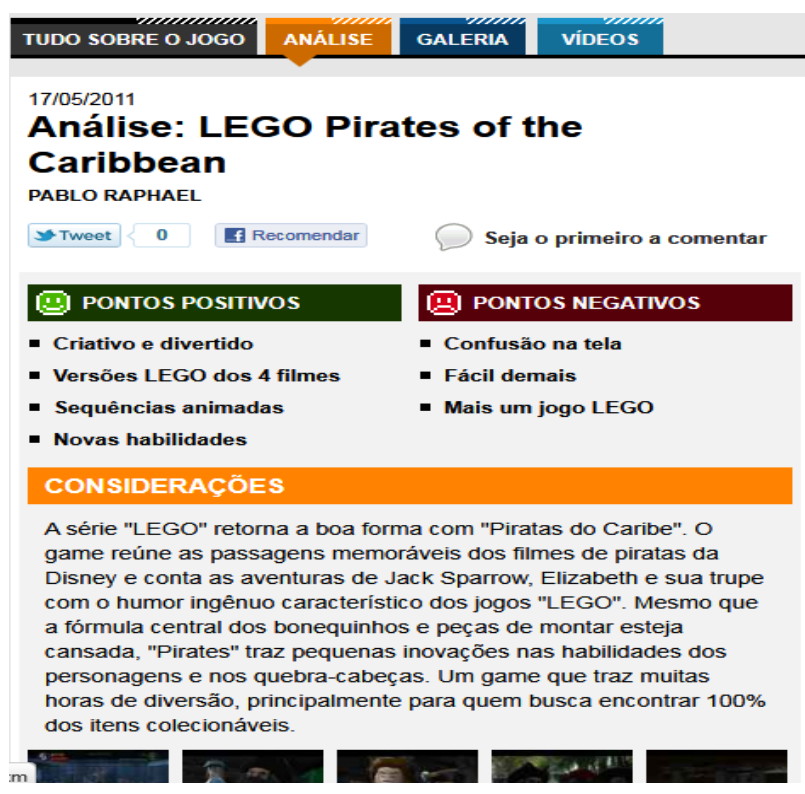

FIGURA 1 - Exemplo de uma análise on line. FONTE - site UOL Jogos 
Sobre as possibilidades colaborativas do site UOL Jogos, isso se torna mais presente não na parte dos comentários, mas na interligação com um fórum que permite uma interação mútua, ao possibilitar um contato conversacional onde alguém pode lançar alguma informação sobre um game que será visível a todos os participantes (Figura 2).

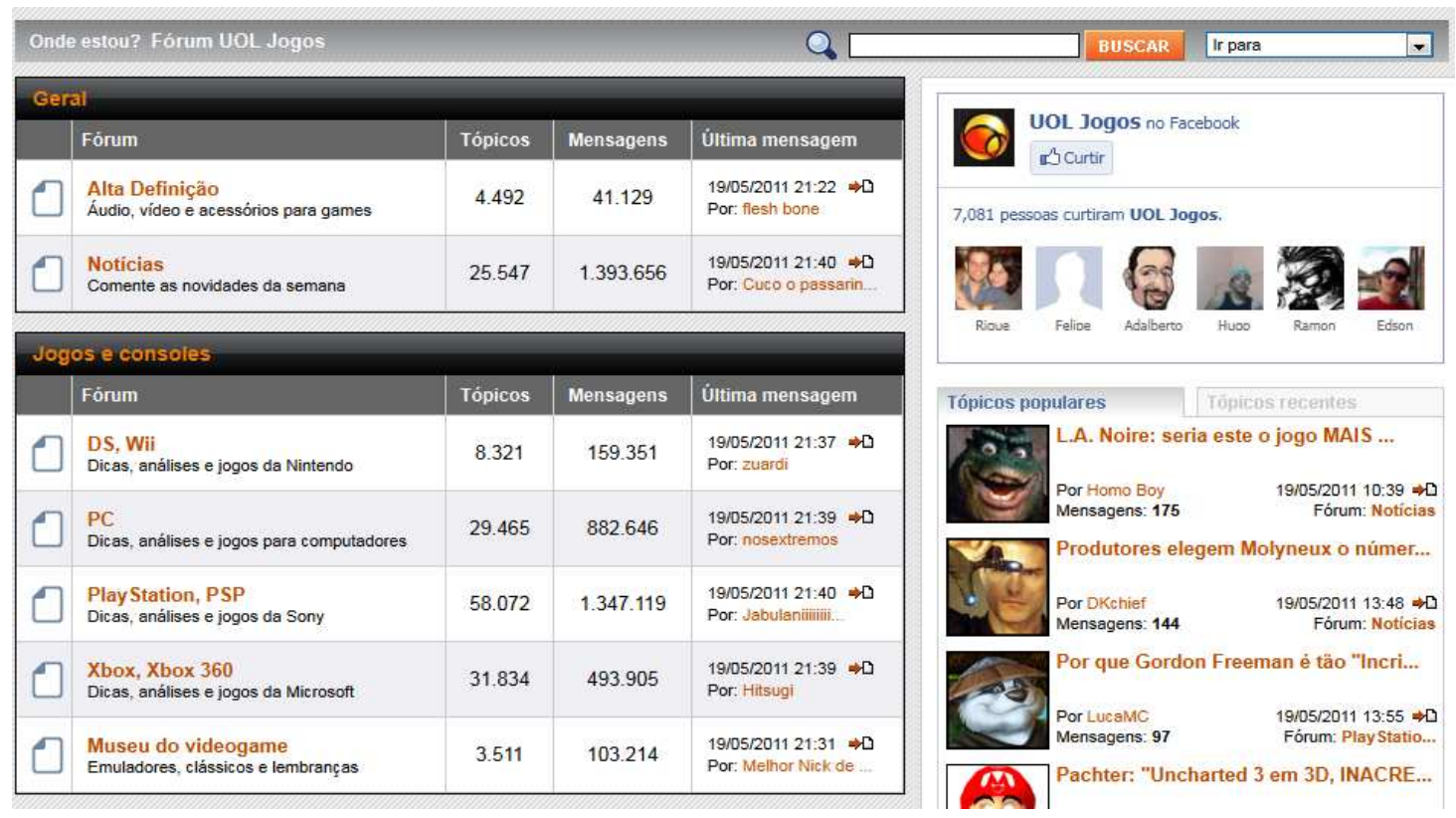

FIGURA 2 - exemplo de um Fórum do UOL Jogos.

FONTE - site UOL Jogos

\section{A Reconstrução Colaborativa de Conteúdos}

O motivo para a produção de um conteúdo colaborativo dessas resenhas está nas possibilidades de interconexões entre diferentes ambiências ou "compartimentos" e entre diferentes pessoas. Por diferentes ambiências queremos dizer diferentes núcleos contextuais que permitem um instantâneo de um determinado fluxo, sob a forma de uma etapa da interação, materializadas em páginas específicas de um determinado site.

Ressaltamos que a reconstrução colaborativa de conteúdos não é algo originado de um consciente coletivo. O encadeamento de opiniões não é visivelmente moderado. A ideia principal é ser parte de um conjunto de visões de aspectos diferentes do produto cultural analisado. Tais visões não 
contribuem necessariamente para a resenha em si, mas para a percepção mais ampla de um grupo de leitores.

Esse conjunto de ideias, de visões caleidoscópicas, torna-se mais presente no fórum do site UOL Jogos, com uma melhor expressão do conceito de interação mútua, reconfigurando a ideia original de emissor e receptor, em um contexto onde todos são interagentes. Entretanto, acrescentemos que, conforme Alex Primo (2008, p.101) "uma interação mútua não deve ser vista como uma soma de ações individuais", ou seja, tal modalidade de interação constitui uma grande inteligência coletiva que usa trailers, imagens, experiência pessoal com determinado produto cultural, resenhas e outras formas de análise, para servir a uma apreciação mais completa de seu objeto. Uma apreciação participante onde a leitura deixa de ser algo solitário e a construção se torna coletiva, em um universo onde um site passa a ser concebido como um ponto de encontro de um determinado grupo.

Assim, a resenha deixa de ser o centro para se tornar, apenas, um eixo orientador, deixando o verdadeiro trabalho de avaliação e interpretação do produto cultural para um grupo de pessoas, mais ou menos organizado em temáticas específicas. Há, então, uma interação própria entre leitores, gerando comentários e discussões.

Mesmo assim, todavia, verificamos que é grande a chance dessas discussões e comentários decaírem para uma espécie de "bobagem coletiva", o que nos faz sugerir a presença de algum tipo mais consistente de moderação - e não, simplesmente, esperar que o público faça tudo.

\section{Considerações finais}

A resenha on line vem se revelando algo mais que uma simples categoria textual do gênero opinativo do jornalismo. Ela é a extensão do produto original cuja fruição não se dá mais apenas pela compra ou captação de seu conteúdo, mas pelas discussões promovidas ao redor dele. Novos conteúdos vão sendo reconstruídos colaborativamente, levando à criação de extensões do produto 
original e a uma ampliação do conceito de fazer resenha (também denominada, dependendo do site, de "crítica" ou "análise").

Vimos que a resenha on line possui uma textualidade mais compacta e com facilidades de acesso por causa de suas possibilidades hipermidiáticas. Além disso, observamos que nas resenhas chamadas de "análises" temos uma espécie de sumário focando apenas os principais pontos de um determinado produto, com apreciações resumidas - isso podendo significar um novo tipo de texto, uma evolução natural da clássica resenha, suprindo sua função de apreciação de um produto cultural.

Outro ponto é que, embora seja possível a participação do diretor de um filme, do escritor de um documento, do desenhista de uma história em quadrinhos, do desenvolvedor de um game etc., não constatamos sua contribuição na construção de uma resenha on line nos casos analisados. Daí, vislumbrarmos a possibilidade de criação de canais específicos nos sites para que estes possam interagir diretamente com os usuários, gerando assim comentários dos próprios autores. O chat, já disponível em vários portais, poderia ser mais um meio ofertado por sites de resenhas on line para colaboração em tempo real.

Acreditamos, então, que a resenha vai sendo desconstruída e reconstruída na web por um público disposto a demonstrar que não se faz mais escrita opinativa como antigamente: fazem-se colaborativamente textos, articulações, discussões etc. Isso permite que tanto os colaboradores quanto os produtores de um objeto cultural tenham um novo material que oportuniza a estes analisar a forma de criação de seu próprio trabalho e que permita ao público em geral sua formação de opinião.

\section{REFERÊNCIAS}

BARRETO, Rachel Cardoso. Crítica ordinária: a crítica de cinema na imprensa brasileira. Belo Horizonte, MG: 2005. 218 f. Dissertação (Mestrado em Comunicação Social), Faculdade de Filosofia e Ciências Humanas da Universidade Federal de Minas Gerais. 
JENKINS, Henry. Cultura da convergência. 2. ed. São Paulo: Aleph, 2009.

MELO, José Marques de. A opinião no jornalismo brasileiro. 2. ed. Petrópolis: Vozes, 1994.

O CAPACITOR. Disponível em: <http://ocapacitor.uol.com.br/>. Acesso em: 07 maio 2011.

OMELETE. Disponível em: <http://www.omelete.com.br/>. Acesso em: 07 maio 2011.

PALACIOS, Marcos. et al. Um mapeamento de características e tendências no jornalismo online brasileiro. Disponível em: $<$ http://www.facom.ufba.br/jol/pdf/2002_palacios_mapeamentojol.pdf>. Acesso em: 30 abr. 2011.

PALACIOS, Marcos. Jornalismo online, informação e memória: apontamentos para debate. Disponível em: <http://www.facom.ufba.br/jol/pdf/2002_palacios_informacaomemoria.pdf>. Acesso em: 07 maio 2011.

PAUL, Nora. Elementos das narrativas digitais. In: FERRARI, Pollyana. Hipertexto, hipermídia: as novas ferramentas da comunicação digital. São Paulo: Contexto, 2007.

PRIMO, Alex. Interação mediada por computador: comunicação, cibercultura, cognição. 2 ed. Porto Alegre: Sulina, 2008.

UOL JOGOS. Disponível em: <http://jogos.uol.com.br/>. Acesso em: 07 maio 2011. 